$$
\begin{aligned}
& \text { ANR/ET/CP--91269 } \\
& \text { CONF-970726--18 }
\end{aligned}
$$

\title{
Crack Initiation and Crack Growth Behavior of Carbon and Low-Alloy Steels*
}

\author{
Daniel J. Gavenda, Paul R. Luebbers, and Omesh K. Chopra \\ Energy Technology Division \\ Argonne National Laboratory \\ 9700 South Cass Avenue \\ Argonne, lllinois 60439 USA

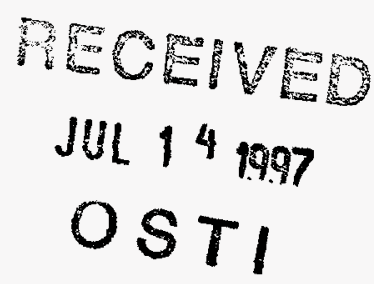

\section{DISCLAIMER}

This report was prepared as an account of work sponsored by an agency of the United States Government. Neither the United States Government nor any agency thereof, nor any of their employees, makes any warranty, express or implied, or assumes any legal liability or responsibility for the accuracy, completeness, or usefulness of any information, apparatus, product, or process disclosed, or represents that its use would not infringe privately owned rights. Reference herein to any specific commercial product, process, or service by trade name, trademark, manufacturer, or otherwise does not necessarily constitute or imply its endorsement, recommendation, or favoring by the United States Government or any agency thereof. The views and opinions of authors expressed herein do not necessarily state or reflect those of the United States Government or any agency thereof.

The submitted manuscript has been
authored by a contractor of the U.S.
Government under contract No. W-31-
109-ENG-38. Accordingly, the U.S.
Government retains a nonexclusive,
royalty-free license to publish or
reproduce the published form of this
contribution, or allow others to do so.
for U.S. Government purposes.

January 1997

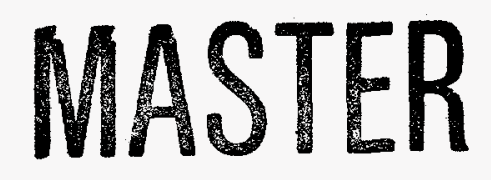

To be presented at 1997 ASME Pressure Vessels and Piping Conference, July 27-31, 1997, Orlando, Florida.

\footnotetext{
*Work supported by the Office of Nuclear Regulatory Research of the U.S. Nuclear Regulatory Commission, under FIN Number W6610; Program Manager: Dr. M. McNeil.
} 


\section{DISCLAMIER}

Portions of this document may be illegible in electronic image products. Images are produced from the best available original document. 


\title{
Crack Initiation and Crack Growth Behavior of Carbon and Low-Alloy Steels
}

\author{
Daniel J. Gavenda, Paul R. Luebbers, and Omesh K. Chopra \\ Energy Technology Division \\ Argonne National Laboratory \\ Argonne, Illinois 60439
}

\begin{abstract}
Section III of the ASME Boiler and Pressure Vessel Code specifies fatigue design curves for structural materials. These curves were based on tests of smooth polished specimens at room temperature in air. The effects of reactor coolant environments are not explicitly addressed by the Code design curves, but recent test data illustrate potentially significant effects of LWR coolant environments on the fatigue resistance of carbon and low-alloy steels. Under certain loading and environmental conditions, fatigue lives of test specimens may be a factor of $\approx 70$ shorter than in air. Results of fatigue tests that examine the influence of reactor environment on crack initiation and crack growth of carbon and low-alloy steels are presented. Crack lengths as a function of fatigue cycles were determined in air by a surface replication technique, and in water by block loading that leaves marks on the fracture surface. Decreases in fatigue life of low-alloy steels in high-dissolved-oxygen (DO) water are primarily caused by the effects of environment during early stages of fatigue damage, i.e., growth of short cracks $<100 \mu \mathrm{m}$ in depth. For crack sizes of $>100 \mu \mathrm{m}$, crack growth rates in high-DO water are higher than in air by one order of magnitude. The effects of LWR environments on growth of short cracks are discussed.
\end{abstract}

\section{Introduction}

The ASME Boiler and Pressure Vessel Code Section III, Subsection NB [1], contains rules for the construction of Class 1 components. Figure I-9.0 of Appendix I to Section III specifies the Code design fatigue curves for the applicable structural materials. However, Section III, Subsection NB-3121, of the Code states that effects of the coolant environment on fatigue resistance of a material are not addressed in these design curves. Recent fatigue strain vs. life (S-N) data [2-10] illustrate potentially significant effects of LWR coolant environments on the fatigue resistance of carbon steels (CSs) and low-alloy steels (LASs). Fatigue lives are significantly reduced when five conditions are satisfied simultaneously, i.e., when applied strain range, service temperature, dissolved oxygen (DO) in the water, and S content of the steel are above minimum threshold levels, and loading strain rate is below a threshold value.

Existing fatigue $\mathrm{S}-\mathrm{N}$ data have been used to define the threshold values of the five critical parameters [2-4]. Although these are the minimum conditions that must be met to produce significant degradation in fatigue life, the actual dependence of fatigue life on these variables involves complex synergistic interactions. Under certain conditions of loading and environment, fatigue lives in the environment can be a factor of 70 lower than those in air. Environmental effects on fatigue life are modest when any one of the threshold conditions is 
not satisfied, i.e., fatigue life is lower by less than a factor of 2 than that in air. Also, studies on fatigue crack growth behavior of carbon and low-alloy steels in LWR environments indicate that flow rate is an important parameter for environmental effects on fatigue life in water $[11,12]$. However, experimental data to establish either the dependence of fatigue life on flow rate or the threshold flow rate for environmental effects on fatigue life are not available.

A program is being conducted at Argonne National Laboratory (ANL) to provide data and models for predicting environmental effects on fatigue design curves and an assessment of the validity of fatigue damage summation in piping and vessel steels under load histories typical of LWR components. Based on the existing fatigue $\mathrm{S}-\mathrm{N}$ data, interim fatigue design curves that address environmental effects on fatigue life of CSs and LASs and austenitic stainless steels have been proposed [13]. Statistical models have been developed for estimating the effects of various material and loading conditions on fatigue life of materials used in the construction of nuclear power plant components [14,15]. The models for carbon and low-alloy steels have been updated because it was determined that in the range of 0.05-0.5 ppm, the effect of DO was more logarithmic than linear [16]. In air, the fatigue life $\mathrm{N}$, defined as the number of cycles required to form a 3-mm-deep crack, of CSs is expressed as

$$
\ln (\mathrm{N})=6.570-0.00133 \mathrm{~T}-1.871 \ln \left(\varepsilon_{\mathrm{a}}-0.11\right)
$$

and that of LASs as

$$
\ln (\mathrm{N})=6.667-0.00133 \mathrm{~T}-1.687 \ln \left(\varepsilon_{\mathrm{a}}-0.15\right),
$$

where applied strain amplitude $\varepsilon_{\mathrm{a}}$ is in $\%$ and temperature $\mathrm{T}$ is in ${ }^{\circ} \mathrm{C}$. In $\mathrm{LWR}$ environments, the fatigue life $\mathrm{N}$ of $\mathrm{CSs}$ is expressed as

$$
\ln (\mathrm{N})=6.186-1.871 \ln \left(\varepsilon_{\mathrm{a}}-0.11\right)+0.1097 \mathrm{~S}^{*} \mathrm{~T}^{*} \mathrm{O}^{*} \dot{\varepsilon}^{*}
$$

and that of LASs as

$$
\ln (\mathrm{N})=5.901-1.687 \ln \left(\varepsilon_{\mathrm{a}}-0.15\right)+0.1097 \mathrm{~S}^{*} \mathrm{~T}^{*} \mathrm{O}^{*} \dot{\varepsilon}^{*}
$$

where $\mathrm{S}^{*}, \mathrm{~T}^{*}, \mathrm{O}^{*}$, and $\dot{\varepsilon}^{*}$ are transformed $\mathrm{S}$ content, temperature, DO, and strain rate, respectively, defined as follows:

$$
\begin{array}{ll}
\mathrm{S}^{*}=\mathrm{S} & (0<\mathrm{S} \leq 0.015 \mathrm{wt} \% \\
\mathrm{S}^{*}=0.015 & (\mathrm{~S}>0.015 \mathrm{wt} . \%) \\
\mathrm{T}^{*}=0 & \left(\mathrm{~T}<150^{\circ} \mathrm{C}\right) \\
\mathrm{T}^{*}=\mathrm{T}-150 & \left(\mathrm{~T}=150-350^{\circ} \mathrm{C}\right) \\
\mathrm{O}^{*}=0 & (\mathrm{DO}<0.05 \mathrm{ppm}) \\
\mathrm{O}^{*}=\ln (\mathrm{DO} / 0.04) & (0.05 \mathrm{ppm} \leq \mathrm{DO} \leq 0.5 \mathrm{ppm}) \\
\mathrm{O}^{*}=\ln (12.5) & (\mathrm{DO}>0.5 \mathrm{ppm}) \\
\dot{\varepsilon}^{*}=0 & (\dot{\varepsilon}>1 \% / \mathrm{s}) \\
\dot{\varepsilon}^{*}=\ln (\dot{\varepsilon}) & (0.001 \leq \dot{\varepsilon} \leq 1 \% / \mathrm{s}) \\
\dot{\varepsilon}^{*}=\ln (0.001) & (\dot{\varepsilon}<0.001 \% / \mathrm{s})
\end{array}
$$

Fatigue evaluation methods for incorporating environmental effects on the fatigue life of carbon and low-alloy steels in LWR environments have also been developed by the 
Environmental Fatigue Data (EFD) Committee of the Thermal and Nuclear Power Engineering Society (TENPES) of Japan [17], and by the Electric Power Research Institute (EPRI) [18]. The Pressure Vessel Research Council (PVRC) has been compiling and evaluating fatigue S-N data related to the effects of LWR coolant environments on the fatigue life of pressure boundary materials [19].

This paper presents the results of fatigue tests that examine the influence of reactor environment on the formation and growth of fatigue cracks in polished smooth specimens of carbon and low-alloy steels. Fatigue tests have been conducted to determine the crack initiation and crack growth characteristics of A533-Gr B low-alloy steel and A106-Gr B carbon steel in air and water environments. Crack lengths as a function of fatigue cycles were determined in air by a surface replication technique, and in water by block loading that leaves marks on the fracture surface. The effects of LWR environments on growth of short cracks are discussed.

\section{Mechanism of Fatigue Crack Initiation}

The fatigue $\mathrm{S}-\mathrm{N}$ curve represents the process of fatigue crack initiation (or fatigue damage accumulation). It specifies, for a given stress or strain amplitude, the number of cycles needed to form an "engineering" crack (e.g., a 3-mm-deep crack), also defined as fatigue life for the material. Deformation and microstructural changes in the surface grains control fatigue cracking. During cyclic straining, irreversibility of dislocation glide leads to the development of surface roughness. Also, strain localization in persistent slip bands (PSBs) results in the formation of extrusions and intrusions. With continued cycling, microcracks ultimately form in PSBs or at the edges of slip-band extrusions. At high strain amplitudes, microcracks form in notches that develop at grain or twin boundaries. Similarly, microcracks can also develop at phase boundaries (e.g., ferrite/pearlite boundaries) or by cracking of second-phase particles (e.g., sulfide or oxide inclusions).

Once a microcrack is formed, it continues to grow along its slip plane or a PSB as a Mode II (shear) crack in Stage I growth (orientation of the crack is usually at $45^{\circ}$ to the stress axis). At low strain amplitudes, a Stage I crack may extend across several grain diameters before the increasing stress intensity of the crack promotes slip on systems other than the primary slip. A dislocation cell structure normally forms at the crack tip. Because slip is no longer confined to planes at $45^{\circ}$ to the stress axis, the crack begins to propagate as a Mode I (tensile) crack, normal to the stress axis in Stage II growth. At high strain amplitudes, the stress intensity is quite large and the crack propagates entirely by Stage II process. The Stage II crack propagation continues until the crack reaches an engineering size $(\approx 3 \mathrm{~mm}$ deep $)$. In air or mildly corrosive environments, Stage II fracture is characterized by fatigue striations.

Fatigue life, or number of allowable cycles, has conventionally been represented by two stages: (a) initiation, which represents the cycles $N_{i}$ for formation of microcracks on the surface; and (b) propagation, which represents cycles $N_{p}$ for propagation of the surface cracks to an engineering size. Thus, fatigue life $\mathrm{N}$ is the sum of the two stages, $\mathrm{N}=\mathrm{N}_{\mathrm{i}}+\mathrm{N}_{\mathrm{p}}$. The former is considered to be sensitive to the stress or strain amplitude, e.g., most of the life may be spent in initiating a crack at low strain amplitudes, whereas cracks initiate easily at high strain amplitudes. 
An alternative approach considers fatigue life to be entirely composed of crack propagation [20]; for polycrystalline materials the period for the formation of surface cracks is zero (Fig. 1). Fatigue damage in a material is the current size of fatigue crack, and damage accumulation is the rate of crack growth. During fatigue loading of smooth test specimens, cracks forms immediately at surface irregularities/discontinuities either already in existence or produced by slip bands, grain boundaries, second-phase particles, etc. Growth of these surface cracks may be divided into three regimes: (a) initial period involving growth of microstructurally small cracks (MSCs) characterized by decelerating crack growth, seen in region $A B$ of Fig. 1; (b) final period of growth characterized by accelerating crack growth, region $C D$; and (c) a transition period controlled by a combination of the two regimes, region $\mathrm{BC}$.

The growth of short cracks below a critical crack length, termed MSCs, is very sensitive to microstructure [21-24]. The MSCs correspond to Stage I cracks and grow along slip planes as shear cracks in the early stage of growth. For MSCs, microstructural effects are strong because of the Stage I growth, i.e., crystallographic growth. The growth rates are markedly decreased by grain boundaries, triple points, and phase boundaries. In ferritic-pearlitic steels, fatigue cracks initiate and propagate preferentially in the ferrite phase that forms as long allotriomorphs at the prior austenite phase boundaries [23,24]. The ferrite-pearlite phase boundaries act as strong barriers to crack propagation, and growth rates decrease significantly when small cracks grow into the pearlite from the ferrite [23]. Limited data suggest that microstructural effects are more pronounced at negative stress ratios; the compressive component of the applied load plays an important role in the formation of Stage I facets and as crack driving force [22].

Fatigue cracks above the critical length of MSCs show little or no influence of microstructure and are termed mechanically small cracks [22]. Their growth rates are higher than those of large cracks because of less crack closure. These mechanically small cracks correspond to Stage II or tensile cracks characterized by striation crack growth, with a fracture surface normal to the maximum principal stress. For ferritic-pearlitic steels, Stage II crack propagation occurs when stress intensity and mode of growth attains a critical condition to break through the pearlite colony and join other ferrite cracks. For a stress ratio of -1 , the transition from MSC to a mechanically small crack has been estimated for several material to be $\approx 8$ times the microstructural unit size [22].

At low stress levels, e.g., $\Delta \sigma_{2}$ in Fig. 1, the transition from MSC growth to accelerating crack growth does not occur, resulting in nonpropagating cracks. This represents the fatigue limit for the smooth specimen. It is not a stress limit below which cracks cannot form, but a limit above which microcracks that form on smooth surfaces can grow to engineering size. Note that large cracks which may preexist in the material, e.g., defects in welded samples, or those created by growth of microcracks at high stresses, can grow at stress levels below the fatigue limit.

Reduction in fatigue life in LWR coolant environments may arise from easy formation of surface microcracks and/or an increase in growth rates of cracks, during either the initial stage of MSCs and shear crack growth or the transition and final stage of tensile crack growth. Carbon and low-alloy steel specimens tested in water show surface micropitting and cavities produced by either corrosion or dissolution of MnS inclusions [6]. These micropits can act as sites for the formation of fatigue cracks. 
Detailed metallographic evaluation of the fatigue specimens [6] and exploratory tests [4,5] have been conducted to evaluate the contributions of environment to the formation of surface microcracks. The results indicate that the reduction in fatigue life in high-DO water is primarily due to environmental effects on crack propagation. Environment appears to have little or no effect on the formation of surface microcracks. Although all specimens tested in water show surface micropitting, there is no indication that these micropits enhance cracking. Irrespective of environment, cracks in carbon and low-alloy steels nucleate either along slip bands, sulfide inclusions, carbide particles, or at the ferrite/pearlite phase boundaries. Examples of such cracks [6] in A106-Gr B carbon steel tested at $288^{\circ} \mathrm{C}$ in water that contained 0.8 ppm DO are shown in Fig. 2.

The environmental enhancement in fatigue crack growth of pressure vessel steels in hightemperature oxygenated water and the effects of sulfur content, loading rate, and flow velocities are well known [25-30]. The enhanced growth rates in LWR environments have been attributed to either slip dissolution [31,32] or hydrogen-induced cracking [33] mechanisms. The requirements for a slip dissolution model are that a protective oxide film is thermodynamically stable to ensure that a crack will propagate with a high aspect ratio without degrading into a blunt pit, and that a strain increment occurs to rupture that film, thereby exposing the underlying matrix to the environment. Once the passive oxide film is ruptured, crack extension is controlled by dissolution of freshly exposed surfaces and the oxidation characteristics. The hydrogen-induced cracking of LASs is explained as follows: hydrogen produced by the oxidation reaction at or near the crack tip is partly absorbed into the metal; the absorbed hydrogen diffuses ahead of the crack tip and interacts with MnS inclusions, leading to formation of cleavage cracks at the inclusion matrix interface; and linkage of the cleavage cracks results in discontinuous crack extension additional to that caused by mechanical fatigue.

Both mechanisms are dependent on oxide rupture rates, passivation rates, and liquid diffusion rates. For environmental effects on fatigue life, a critical level of sulfide ions is needed at the crack tip. Dissolution of MnS inclusions changes the water chemistry near the crack tip, making it more aggressive. This results in enhanced crack growth rates because either (a) the dissolved sulfides decrease the repassivation rate, which increases the amount of metal dissolution for a given oxide rupture rate [32]; or (b) the dissolved sulfide poisons the recombination of $\mathrm{H}$ atoms liberated by corrosion, which enhances $\mathrm{H}$ uptake by the steel at the crack tip. Recent studies, based on a balance between sulfide supply rate due to exposure of sulfide inclusions by advancing crack and mass transport away from the crack tip by diffusion, indicate that a critical velocity of $5 \times 10^{-7} \mathrm{~mm} / \mathrm{s}$ and a minimum crack size of $2.5 \mathrm{~mm}$ are necessary to produce the sulfur concentration for environmentally assisted enhancement of crack growth in low-DO environments [25]. For smooth cylindrical fatigue specimens, fatigue life is defined as the number of cycles to produce $a \approx 3 \mathrm{~mm}$ crack. Consequently, environmental effects should not decrease fatigue life in low-DO water. The existing fatigue S$\mathrm{N}$ data are consistent with these results; fatigue life of CSs and LASs in low-DO water $(<0.01 \mathrm{ppm} \mathrm{DO})$ at $288^{\circ} \mathrm{C}$ is lower than that in air by a factor of $<2$. However, it is plausible that in high-DO water environments, MSCs or nonpropagating cracks could grow by anodic dissolution or other processes thereby decreasing the fatigue life of the material. 


\section{Experimental}

Low-cycle fatigue tests have been conducted on A106-Gr B carbon steel and A533-Gr B low-alloy steel. The A533-Gr B material was obtained from the lower head of the Midland reactor vessel, which was scrapped before the plant was completed. The A106-Gr B material was obtained from a 508-mm-diameter schedule 140 pipe fabricated by the Cameron Iron Works, Houston, TX. The chemical compositions of the two materials are given in Table 1, and average room-temperature tensile properties provided by the material suppliers are given in Table 2. The carbon steel has a pearlitic structure, whereas the low-alloy steel consists of tempered bainite. Smooth cylindrical specimens with $9.5-\mathrm{mm}$ diameter and 19-mm gage length were used for the fatigue tests. Specimen gage length was given a $1-\mu \mathrm{m}$ surface finish in the axial direction to prevent circumferential scratches that might act as sites for crack initiation.

The tests in water were conducted in a small autoclave under stroke control where the specimen strain was controlled between two locations outside the autoclave. All tests were conducted at $288^{\circ} \mathrm{C}$ with fully reversed axial loading (i.e., $\mathrm{R}=-1$ ) and a triangular or sawtooth waveform. The strain rate for the triangular wave and fast-loading half of the sawtooth wave was $0.4 \% / \mathrm{s}$. Tests in air were performed under strain control with an axial extensometer; specimen strain between the two locations used in the water tests was also recorded. Information from the air tests was used to determine the stroke required to maintain constant strain in the specimen gage length for tests in water; the stroke is gradually increased during the test to account for cyclic hardening of the material and to maintain constant strain in the specimen gage section. Details regarding the test facility and procedure are described in Ref. 2.

Surface replication by an acetate film was employed to measure surface length of cracks in specimens tested in room temperature air. This technique provides $\approx 1 \mu \mathrm{m}$ resolution of the surface and allows surface features such as PSB and cracking to be identified. The tests were interrupted periodically to allow for surface replication. A detailed examination of the gage surface of the specimen was conducted to establish the morphology of final fatigue crack. The region on surface replicas corresponding to the final crack was examined to determine the length of surface cracks as a function of fatigue cycles.

The crack morphology and length of the final crack for A533-Gr B specimen tested at $0.75 \%$ strain range with a saw-tooth waveform are shown in Fig. 3 (letters denote reference points used to locate the same regions on the replicas). Surface crack lengths were used as reference markers to define probable crack fronts on the fracture surface. Fatigue striations on the fracture surface were used as guidelines to determine the shape of the crack fronts. The probable crack fronts for the surface crack in Fig. 3, after 5316, 5779, 5955, and 6195 cycles, are shown in Fig. 4. The results indicate that three cracks merged to form the final fracture surface. The primary crack initiated near an inclusion and reached a surface length of $\approx 100 \mu \mathrm{m}$ after 3062 cycles (i.e., $\approx 50 \%$ of fatigue life). Two secondary cracks merged with the primary crack after $\approx 5700$ and 6000 cycles. Crack depth, a, was determined from the surface crack length $S$ by the relationship

$$
\frac{\mathrm{a}}{\mathrm{S}}=\frac{1}{\pi}
$$


The calculated values agree closely with measurements of the probable crack depth on the fracture surface.

For the tests in high-temperature water, crack growth characteristics were determined with block loading, e.g., the slow/fast fatigue tests were interrupted each period $\approx 10 \%$ of life, and the specimen was subjected to a block of fast/fast cycles at either the same or a lower strain range. The block of fast/fast cycles leaves a beach mark on the fracture surface that can be used to characterize crack size as a function of fatigue cycles for the slow/fast test. This method has been used successfully to characterize crack growth in A333-Gr 6 carbon steel tested in $288^{\circ} \mathrm{C}$ water with $1 \mathrm{ppm}$ DO [9]. Photomicrograph of the fracture surface of slow/fast test at $0.75 \%$ strain range interrupted every 50 cycles and subjected to 170 cycles of fast/fast loading at $0.4 \%$ strain range is shown in Fig. 5 . Beach marks produced from four of the five fast/fast loading sequences at the low strain range can be seen clearly on the fracture surface.

\section{Crack Initiation and Growth Characteristics}

\section{Fatigue Life}

The results of room-temperature tests in air with surface replication and block loading tests in water at $288^{\circ} \mathrm{C}$ are given in Table 3. Relevant data obtained earlier [2-5] on A533-Gr B and A106-Gr B steels in air and water environments are also listed in the table. The results from the present study and data obtained earlier are compared in Figs. 6-8. Estimates of fatigue lives based on the statistical models, Eqs. 1-3, are also included in the figures. The recent test results are consistent with the earlier data.

At room temperature, the fatigue life in water is $\approx 50 \%$ lower than in air. The difference in fatigue lives of the tests at 0.4 and $0.004 \% / \mathrm{s}$ strain rate may be attributed to experimental scatter and are not caused by strain rate effects. Although the available $\mathrm{S}-\mathrm{N}$ data indicate that in air, strain rate may influence fatigue life of some CSs and LASs, these effects occur in the temperature range for dynamic strain aging $\left(200-370^{\circ} \mathrm{C}\right)$ [4]. In room-temperature air, strain rate has little or no effect on the fatigue life of CSs and LASs.

The results of the block loading tests are consistent with those conducted with constant strain range and strain rate (Figs. 7 and 8). Both A533-Gr B LAS and A106-Gr B CS show significant reduction in fatigue life in high-DO water at $288^{\circ} \mathrm{C}$ and a strong dependence on strain rate. Fatigue life decreases rapidly with decreasing strain rate. However, there are a few differences between the tests with block loading and those at constant strain range and rate. For both A533-Gr B and A106-Gr B steels, the fatigue lives of specimens subjected to block loading are consistently lower than those subjected to constant strain range and strain rate. The fatigue lives, expressed as cumulative usage factor (CUF), were estimated from the statistical model and are listed in Table 3 . For a specific test conditions, fatigue usage factor is expressed as the ratio of the observed and estimated values of fatigue life; CUF is the sum of individual usage factors. Low values of CUF have also been observed for block loading tests on A333-Gr B steel in $288^{\circ} \mathrm{C}$ water with $1 \mathrm{ppm}$ DO [9].

The fracture behavior for block loading tests is also different then that for constant strain tests. Micrographs of the fracture surface of A533-Gr B specimens tested at 0.38 and $0.82 \%$ 
strain range (Tests 1803 and 1815, respectively) are shown in Fig. 9. Both fracture surfaces consist of several cracks that initiate at different axial and circumferential locations. These cracks do not merge into a single primary crack. The fracture surface of specimens tested at constant strain range typically consist of a single crack, or a few cracks that merge to form the final fracture surface, e.g., three cracks merged to form the final fracture surface in Fig. 3.

\section{Fatigue Crack Depth}

For the tests in air and water environments, the depth of the largest crack is plotted as a function of fatigue cycles in Fig. 10, and as a function of fractional life in Fig. 11. The results indicate that in RT air, $\approx 10 \mu \mathrm{m}$ cracks form quite early during fatigue, e.g., $<10 \%$ of fatigue life. Also, depth of the largest crack is $<100 \mu \mathrm{m}$ at half life. The results in high-DO water show that the decrease in fatigue life of both A106-Gr B CS and A533-Gr B LAS is primarily caused by the effects of environment during early stages of fatigue damage, i.e., growth of cracks $<100 \mu \mathrm{m}$ in depth (Stage I crack growth). For the same life fraction, crack depth is greater in high- or low-DO water than in air. At $\approx 0.8 \%$ strain range, only $30-50$ cycles are needed to form a $100-\mu \mathrm{m}$ crack in high-DO water (average growth rate of $2-3 \mu \mathrm{m} /$ cycle), whereas it takes more than 3000 cycles to form a $100 \mu \mathrm{m}$ crack in air (average growth rate of $0.033 \mu \mathrm{m} / \mathrm{cycle}$ ). In low-DO PWR environment, the growth of cracks is faster than in air but slower than that in high-DO water.

Figure 11 shows that both in air and water environments, fatigue crack size at different life fractions is independent of strain range and strain rate, and also the DO content in water. The depth of the largest crack at different life fractions is approximately the same at 0.75 and $0.4 \%$ strain ranges. These results show good agreement with earlier studies on CSs [23,34] and LASs [35]; see Fig. 12; crack depth was determined from the surface crack length by using Eq. 4. These results indicate that for strain or stress ranges above the fatigue limit, linear damage summation (Miner's rule) is valid for carbon and low-alloy steels both in air and water environments.

\section{Crack Growth Rate}

The crack growth rates determined from the crack depth vs cycles data of Fig. 10 are plotted as a function of crack depth in Fig. 13. The results indicate that for the same crack depth, growth rates for the tests at $0.8 \%$ strain range are higher than those at $0.4 \%$ strain range. At both 0.8 and $0.4 \%$ strain range, crack growth rates in high-DO water are one order of magnitude higher than in air. Crack growth rates in low-DO PWR environment are higher than those in air by a factor of 2 to 3 . As discussed in the previous section, the average growth rate during the early stage of fatigue damage is $\approx 2.5,0.22$ and $0.033 \mu \mathrm{m} /$ cycle, respectively, in high-DO water, low-DO water, and air environments. At $0.8 \%$ strain range, the probable growth rates during the early stage of fatigue damage in air and low- and high-DO water are shown as dotted lines in Fig. 13.

\section{Metallographic Examination}

A detailed examination of the fatigue test specimens was conducted to investigate the role of high-temperature oxygenated water on fatigue cracking. Micrographs of longitudinal sections of A533-Gr B and A106-Gr B specimens tested in air, high-DO, and PWR 
environments at $288^{\circ} \mathrm{C}, \approx 0.8 \%$ strain range, and a slow/fast waveform (sawtooth) are shown in Fig. 14. For both steels, the formation and growth of surface cracks appear to be different in high-DO water than in air or simulated PWR water. In air and low-DO PWR environments, surface cracks grow as Mode II (shear) crack in Stage I growth along planes usually $45^{\circ}$ to the stress axis. The Stage I crack extends across several grains until the increasing stress intensity of the crack promotes slip on systems other than the primary slip, and the crack begins to propagate as Mode I (tensile) crack normal to the stress axis. Furthermore, for A106Gr B carbon steel, the Stage I crack growth occurs entirely along the soft ferrite grains, avoiding the relatively hard pearlite regions.

In high-DO water, the surface cracks appear to grow entirely as Mode I tensile cracks normal to the stress axis. For A106-GR B carbon steel, cracks propagate across both ferrite and pearlite regions. The absence of Stage I crack growth suggest that factors other than mechanical fatigue are important for growth of surface cracks in high-DO water. These results are consistent with slip dissolution model for enhanced crack growth rates in LWR environments.

\section{Discussion}

The results from the present study indicate that the decrease in fatigue life of carbon and low-alloy steels in high-DO water is primarily caused by the effects of environment on the growth of short crack. Relative to air, crack growth rates in high-DO water are nearly two orders of magnitude higher during the initial stages of fatigue damage (for crack sizes $<100 \mu \mathrm{m}$ ), and are one order of magnitude higher for crack sizes $>100 \mu \mathrm{m}$. Metallographic examination of the test specimens indicate that in high-DO water, surface cracks grow entirely as tensile cracks normal to the stress. In air, growth of surface cracks occurs initially as shear cracks $\approx 45^{\circ}$ to the stress axis, and then as tensile cracks normal to the stress axis when slip is no longer confined to planes at $45^{\circ}$ to the stress axis.

These results suggest that in LWR environments, the growth of MSCs occurs by anodic dissolution; the growth rates depend on DO level in water and $\mathrm{S}$ content in the steel. When the applied strain is greater than the threshold strain required to rupture the passive oxide film, crack extension occurs by anodic dissolution of freshly exposed surfaces and the oxidation characteristics. Studies on the effects of strain rate change on fatigue life of CSs and LASs in high-DO water also show that the applied strain must exceed a threshold value to rupture the passive surface film in order for environmental effects to occur [2-4]. The crack tip strain rate is used for describing the oxide rupture at the crack tip during crack advance. The critical crack tip velocity depends on sulfur content in the steel and sulfide ion diffusion away from the crack tip in water. The environmentally assisted crack growth rate $\mathrm{V}$ is related to the crack tip strain rate $\dot{\varepsilon}_{\text {ct }}$ by the relationship

$$
\mathrm{V}=\mathrm{A}\left(\dot{\varepsilon}_{\mathrm{ct}}\right)^{\mathrm{n}}
$$

where $\mathrm{V}$ is in $\mathrm{cm} / \mathrm{s}, \dot{\varepsilon}_{\mathrm{ct}}$ is in $\mathrm{s}^{-1}$, and the constants $\mathrm{A}$ and $\mathrm{n}$ depend on the material and environmental conditions at the crack tip. There is a lower limit of crack propagation rate associated either with blunting when the crack tip cannot keep up with general corrosion rate of the crack sides or the fact that a critical level of sulfide ions cannot be maintained at the 
crack tip. The crack propagation rate at which this transition occurs will depend on DO level, flow rate, etc. Based on these factors, the maximum and minimum environmentally controlled crack propagation rates have been defined [31]. For crack-tip sulfide ion concentrations above the critical level,

$$
\mathrm{V}=2.25 \times 10^{-4} \dot{\varepsilon}_{\mathrm{ct}}{ }^{0.35}
$$

and for crack tip sulfide ion concentrations below the critical level,

$$
\mathrm{V}=10^{-2} \dot{\varepsilon}_{\mathrm{ct}}^{1.0}
$$

where $\mathrm{V}$ is in $\mathrm{cm} \mathrm{s}^{-1}$ and $\dot{\varepsilon}_{\mathrm{ct}}$ is in $\mathrm{s}^{-1}$. Assuming that the crack tip strain rate $\dot{\varepsilon}_{\mathrm{ct}}$ is the same as the applied strain rate $\dot{\varepsilon}_{\text {app }}$ and crack advance due to mechanical fatigue is insignificant during the initial stages of fatigue damage, the crack advance (in $\mathrm{cm}$ ) per cycle is given by

$$
\Delta \mathrm{a}_{\mathrm{r}}=2.25 \times 10^{-4}\left(\Delta \varepsilon-\varepsilon_{f}\right)\left(\dot{\varepsilon}_{\mathrm{app}}\right)^{-0.65}
$$

where $\varepsilon_{f}$ is the threshold strain increment needed to rupture the oxide film. For A533-Gr B steel, the threshold strain range for environmentally assisted reduction in fatigue life is $\approx 0.36 \%$ $[3,4]$. For a applied tensile strain rate of $0.004 \% / \mathrm{s}$, from Eq. 7, the crack growth during the initial stage of fatigue damage (for crack sizes $<100 \mu \mathrm{m}$ ) is $\approx 7$ and $0.65 \mu \mathrm{m} /$ cycle at 0.8 and $0.4 \%$ strain range, respectively. These values are higher than the measured average crack growth rates by a factor of 2 to 3 (Fig. 13).

The measured crack growth rates are compared with the current and proposed [35] ASME Section XI reference crack growth curves for carbon and low-alloy steels in Fig. 15. The data for A333-Gr 6 carbon steel in $288^{\circ} \mathrm{C}$ water with 1 or $0.005 \mathrm{ppm}$ DO [9] are also included in the figure. For the cylindrical fatigue specimens, the stress intensity ranges $\Delta \mathrm{K}$ were determined from the values of $\Delta \mathrm{J}$, which for a small half-circular surface crack [36] are given by

$$
J=3.2\left(\frac{\sigma^{2}}{2 E}\right) a+5.0\left(\frac{\sigma \varepsilon_{p}}{1+n}\right) a,
$$

where $\mathrm{E}$ is the elastic modulus, $\varepsilon_{p}$ is nominal plastic strain, and a is crack depth. The stress intensities associated with conventional cylindrical fatigue specimens were modified on the basis of rigorous finite-element models [37]. The cyclic stress $\sigma$ and strain $\varepsilon$ is defined as

$$
\varepsilon=\frac{\sigma}{E}+\left(\frac{\sigma}{\mathrm{A}}\right)^{\mathrm{n}}
$$

where constant A and exponent $\mathrm{n}$ were determined from the experimental data [2-4]. The results show good agreement with the proposed reference curves. The growth rates for the A333-Gr 6 steel in low-DO water seem to be significantly higher than the ANL data on A533Gr B steel tested under similar conditions. The results also suggest that for smooth cylindrical specimens, the threshold value of $\Delta \mathrm{K}$ below which environmetal effects on growth rates do not occur is either very low or does not exist. 


\section{Conclusions}

Fatigue tests have been conducted to determine the crack initiation and crack growth characteristics of carbon and low-alloy steels in air and LWR environments. Results of fatigue tests that examine the influence of reactor environment on formation and growth of short cracks in A533-Gr B low-alloy steel and A106-Gr B carbon steel are presented. Crack lengths as a function of fatigue cycles were determined in air and water environments. The significant results are summarized below.

(i) In air, fatigue cracks, $10 \mu \mathrm{m}$ or longer, form quite early during fatigue $(<10 \%$ of life) even at low strain ranges $(\approx 0.4 \%)$. The largest crack is $<100 \mu \mathrm{m}$ at half life. The results suggest that linear damage summation should be valid for strain or stress ranges above the fatigue limit, e.g., the crack depth vs life fraction plots are approximately the same over a wide range of strain or stress range.

(ii) The decrease in fatigue life of carbon and low-alloy steels in high-DO water is primarily caused by the effects of environment on the growth of short crack. Relative to air, crack growth rates in high-DO water are nearly two orders of magnitude higher during the initial stages of fatigue damage (for crack sizes $<100 \mu \mathrm{m}$ ), and are one order of magnitude higher for crack sizes $>100 \mu \mathrm{m}$.

(iii) In high-DO water, the surface cracks appear to grow entirely as Mode I tensile cracks normal to the stress axis. In air or low-DO water, growth of surface cracks initially occurs as shear cracks $\approx 45^{\circ}$ to the stress axis.

(iv) The results from the present study are consistent with slip dissolution model for enhanced crack growth rates in LWR environments.

\section{Acknowledgments}

The authors thank W. F. Burke, T. M. Galvin, and J. Tezack for their contributions to the experimental effort. This work was sponsored by the Office of Nuclear Regulatory Research, U.S. Nuclear Regulatory Commission, FIN Number W6610; Program Manager: Dr. M. McNeil.

\section{References}

1. ASME Boiler and Pressure Vessel Code Section III - Rules for Construction of Nuclear Power Plant Components, The American Society of Mechanical Engineers, New York, 1994 Ed.

2. Chopra, O. K., and Shack, W. J., "Effects of LWR Environments on Fatigue Life of Carbon and Low-Alloy Steels," in Fatigue and Crack Growth: Environmental Effects, Modeling Studies, and Design Considerations, PVP Vol. 306, S. Yukawa, ed., American Society of Mechanical Engineers, New York, pp. 95-109, 1995. 
3. Chopra, O. K., and Shack, W. J., "Effects of Material and Loading Variables on Fatigue Life of Carbon and Low-Alloy Steels in LWR Environments," in Transactions of 13th Int. Conf. on Structural Mechanics in Reactor Technology (SMiRT 13), Vol. II, M. M. Rocha and J. D. Riera, eds., Escola de Engenharia - Universidade Federal do Rio Grande do Sul, Porto Alegre, Brazil, pp. 551-562, 1995.

4. Chopra, O. K., and Shack, W. J., "Evaluation of Effects of LWR Coolant Environments on Fatigue Life of Carbon and Low-Alloy Steels," to be published in Proc. of Symposium on Effects of the Environment on the Initiation of Crack Growth, ASTM STP 1298, American Society for Testing and Materials, Philadelphia, 1997.

5. Chopra, O. K., and Shack, W. J., "Effects of LWR Coolant Environments on Fatigue S-N Curves for Carbon and Low-Alloy Steels," in Pressure Vessel and Piping Code and Standards, PVP Vol. 339, T. S. Esselman, ed., American Society of Mechanical Engineers, New York, pp. 185-198, 1996.

6. Chopra, O. K., Michaud, W. F., Shack, W. J., and Soppet, W. K., "Fatigue of Ferritic Steels," in Environmentally Assisted Cracking in Light Water Reactors, Semiannual Report, April-September 1993, NUREG/CR-4667 Vol. 17, ANL-94/16, pp. 1-22, June 1994.

7. Higuchi, M., and Iida, K., "Fatigue Strength Correction Factors for Carbon and Low-Alloy Steels in Oxygen-Containing High-Temperature Water," Nucl. Eng. Des. 129, pp. 293-306, 1991.

8. Higuchi, M., Iida, K., and Asada, Y., "Effects of Strain Rate Change on Fatigue Life of Carbon Steel in High-Temperature Water," in Fatigue and Crack Growth: Environmental Effects, Modeling Studies, and Design Considerations, PVP Vol. 306, S. Yukawa, ed., American Society of Mechanical Engineers, New York, pp. 111-116,1995.

9. Higuchi, M., Iida, K., and Asada, Y., "Effects of Strain Rate Change on Fatigue Life of Carbon Steel in High-Temperature Water," to be published in Proc. of Symposium on Effects of the Environment on the Initiation of Crack Growth, ASTM STP 1298, American Society for Testing and Materials, Philadelphia, 1997.

10. Nakao, G., Kanasaki, H., Higuchi, M., Iida, K., and Asada, Y., "Effects of Temperature and Dissolved Oxygen Content on Fatigue Life of Carbon and Low-Alloy Steels in LWR Water Environment," in Fatigue and Crack Growth: Environmental Effects, Modeling Studies, and Design Considerations, PVP Vol. 306, S. Yukawa, ed., American Society of Mechanical Engineers, New York, pp. 123-128, 1995.

11. Lenz, E., Wieling, N., and Munster, H., "Influence of Variation of Flow Rates and Temperature on the Cyclic Crack Growth Rate under BWR Conditions," in Proc. 3rd Intl. Symp. on Environmental Degradation of Materials in Nuclear Power Systems - Water Reactors, G. J. Theus and J. R. Weeks, eds., The Metallurgical Society, Warrendale, PA, pp. 283-288, 1988.

12. James, L. A., "The Effect of Water Flow Rate Upon the Environmentally-Assisted Cracking Response of a Low-Alloy Steel," J. Pressure Vessel Technol. 117 (3), pp. 238-244, 1995. 
13. Majumdar, S., Chopra, O. K., and Shack, W. J., "Interim Fatigue Design Curves for Carbon, Low-Alloy, and Austenitic Stainless Steels in LWR Environments," NUREG/CR5999, ANL-93/3, April 1993.

14. Keisler, J., Chopra, O. K., and Shack, W. J., "Fatigue Strain-Life Behavior of Carbon and Low-Alloy Steels. Austenitic Stainless Steels, and Alloy 600 in LWR Environments," NUREG/CR-6335, ANL-95/15, Aug. 1995.

15. Keisler, J., Chopra, O. K., and Shack, W. J., "Fatigue Strain-Life Behavior of Carbon and Low-Alloy Steels, Austenitic Stainless Steels, and Alloy 600 in LWR Environments," Nucl. Eng. Des. ???, pp. ???, 1996.

16. Chopra, O. K., presented at the joint meeting of the working groups on Evaluation Methods and S/N Data Analysis, Pressure Vessel Research Council, April 1996, Orlando, FL.

17. Higuchi, M., "Progress Report on Experimental Research on Fatigue Life in LWR Environment, prepared by Japanese EFD Committee of the Thermal and Nuclear Power Engineering Society, presented at the Pressure Vessel Research Council Fall Meeting, Oct. 9-11, 1995, Columbus, OH.

18. Mehta, H. S., and Gosselin, S. R., "An Environmental Factor Approach to Account for Reactor Water Effects in Light Water Reactor Pressure Vessel and Piping Fatigue Evaluations," in Fatigue and Fracture Volume 1, PVP Vol. 323, H. S. Mehta, ed., American Society of Mechanical Engineers, New York, pp. 171-185, 1996.

19. Van Der Sluys, W. A., and Yukawa, S., "Status of PVRC Evaluation of LWR Coolant Environmental Effects on the S-N Fatigue Properties of Pressure Boundary Materials," in Fatigue and Crack Growth: Environmental Effects, Modeling Studies, and Design Considerations, S. Yukawa, ed., American Society of Mechanical Engineers, New York, pp. 47-58, 1995.

20. Miller, K. J., "Damage in Fatigue: A New Outlook," in International; Pressure Vessels and Piping Codes and Standard: Volume 1 - Current Applications, PVP Vol. 313-1, K. R. Rao and Y. Asada, eds., American Society of Mechanical Engineers, New York, pp. 191-192, 1995.

21. Tokaji, K., Ogawa, T., and Harada, Y., "The Growth of Small Fatigue Cracks in a Low Carbon Steel; The Effect of Microstructure and Limitations of Linear Elastic Fracture Mechanics," Fatigue Fract. Engng. Mater. Struct. 9, pp. 205-217, 1986.

22. Tokaji, K., and Ogawa, T., "The Growth of Microstructurally Small Fatigue Cracks in Metals," in Short Fatigue Cracks, ESIS 13, M. J. Miller and E. R. de los Rios, eds., Mechanical Engineering Publication, London, pp. 85-99, 1992.

23. Tokaji, K., Ogawa, T., and Osako, S., "The Growth of Microstructurally Small Fatigue Cracks in a Ferritic-Pearlitic Steel," Fatigue Fract. Engng. Mater. Struct. 11, pp. 331-342, 1988. 
24. de los Rios, E. R., Navarro, A., and Hussain, K., "Microstructural Variations in Short Fatigue Crack Propagation of a C-Mn Steel," in Short Fatigue Cracks, ESIS 13, M. J. Miller and E. R. de los Rios, eds., Mechanical Engineering Publication, London, pp. 115-132, 1992.

25. Wire, G. L., and Li, Y. Y., "Initiation of Environmentally-Assisted Cracking in Low-Alloy Steels," in Fatigue and Fracture Volume 1, PVP Vol. 323, H. S. Mehta, ed., American Society of Mechanical Engineers, New York, pp. 269-289, 1996.

26. Cullen, W. H., Kemppainen, M., Hänninen, H., and Törrönen, K., "The Effects of Sulfur Chemistry and Flow Rate on Fatigue Crack Growth Rates in LWR Environments," NUREG/CR-4121 (1985).

27. Bulloch, J. H., "Environmental Assisted Cracking Phenomena in Reactor Pressure Vessel Steel - The Role of Manganese Sulphide Segregation," in Proc. 3rd Intl. Symp. on Environmental Degradation of Materials in Nuclear Power Systems - Water Reactors, G. J. Theus and J. R. Weeks, eds., The Metallurgical Society, Warrendale, PA, pp. 261-267, 1988.

28. Van Der Sluys, W. A., and Emanuelson, R. H., "Environmental Acceleration of Fatigue Crack Growth in Reactor Pressure Vessel Materials and Environments," in Environmentally Assisted Cracking: Science and Engineering, ASTM STP 1049, W. B. Lisagor, T. W. Crooker, and B. N. Leis, eds., American Society for Testing and Materials, Philadelphia, PA, pp. $117-135,1990$.

29. Auten, T. A., Hayden, S. Z., and Emanuelson, R. H., "Fatigue Crack Growth Rate Studies of Medium Sulfur Low Alloy Steels Tested in High Temperature Water," in Proc. 6th Intl. Symp. on Environmental Degradation of Materials in Nuclear Power Systems - Water Reactors, R. E. Gold and E. P. Simonen, eds., The Metallurgical Society, Warrendale, PA, pp. 35-40, 1993.

30. Atkinson, J. D., Yu, J., and Chen, Z.-Y., "An Analysis of the Effects of Sulfur Content and Potential on Corrosion Fatigue Crack Growth in Reactor Pressure Vessel Steels," Corros. Sci. 38 (5), pp. 755-765, 1996.

31. Ford, F. P., Ranganath, S., and Weinstein, D., "Environmentally Assisted Fatigue Crack Initiation in Low-Alloy Steels - A Review of the Literature and the ASME Code Design Requirements," EPRI Report TR-102765, Aug. 1993.

32. Ford, F. P., "Overview of Collaborative Research into the Mechanisms of Environmentally Controlled Cracking in the Low Alloy Pressure Vessel Steel/Water System," in Proc. 2nd Int. Atomic Energy Agency Specialists' Meeting on Subcritical Crack Growth, NUREG/CP0067, MEA-2090, Vol. 2, pp. 3-71, April 1986.

33. Hänninen, H., Törrönen, K., and Cullen, W. H., "Comparison of Proposed Cyclic Crack Growth Mechanisms of Low Alloy Steels in LWR Environments," in Proc. 2nd Int. Atomic Energy Agency Specialists' Meeting on Subcritical Crack Growth, NUREG/CP-0067, MEA2090, Vol. 2, pp. 73-97, April 1986. 
34. C. M. Suh, R. Yuuki, and H. Kitagawa, "Fatigue Microcracks in a Low Carbon Steel," Fatigue Fract. Engng. Mater. Struct. 8, 193-203 (1985).

35. E. D. Eason, E. E. Nelson, and J. D. Gilman, "Modeling of Fatigue Crack Growth Rate for Ferritic Steels in Light Water Reactor Environments," PVP-Vol. 286, Changing Priorities of Code and Standards, ASME, pp. 131-142, 1994.

36. N. E. Dowling, "Crack Growth During Low-Cycle Fatigue of Smooth Axial Specinmens," in Cyclic Stress-Strain and Plastic Deformation Aspects of Fatigue CRack Growth, ASTM STP 637, American Society for Testing and Materials, Philadelphia, PA, pp. 97-121, 1977.

37. O'Donnell, T. P., and O'Donnell, W. J., "Stress Intensity Values in Conventional S-N Fatigue Specimens," in Fatigue and Crack Growth: International Pressure Vessels and Piping Codes and Standards: Volume 1 - Current Applications, PVP Vol. 313-1, K. R. Rao and Y. Asada, eds., American Society of Mechanical Engineers, New York, pp. 195-197, 1995. 
Table 1. Chemical composition (wt.\%) of ferritic steels used for fatigue tests

\begin{tabular}{lllllllllll}
\hline Material & Source & $\mathrm{C}$ & $\mathrm{P}$ & $\mathrm{S}$ & $\mathrm{Si}$ & $\mathrm{Fe}$ & $\mathrm{Cr}$ & $\mathrm{Ni}$ & $\mathrm{Mn}$ & $\mathrm{Mo}$ \\
\hline $\begin{array}{l}\text { A106- } \\
\text { Gr B }\end{array}$ & ANL & 0.29 & 0.013 & 0.015 & 0.25 & $\mathrm{Bal}$ & 0.19 & 0.09 & 0.88 & 0.05 \\
& & & & & & & & & & \\
& Supplier & 0.29 & 0.016 & 0.015 & 0.24 & $\mathrm{Bal}$ & - & - & 0.93 & - \\
$\mathrm{A533-}$ & ANL & 0.22 & 0.010 & 0.012 & 0.19 & $\mathrm{Bal}$ & 0.18 & 0.51 & 1.30 & 0.48 \\
Gr B & & & & & & & & & & \\
& Supplier & 0.20 & 0.014 & 0.016 & 0.17 & $\mathrm{Bal}$ & 0.19 & 0.50 & 1.28 & 0.47 \\
\hline
\end{tabular}

\footnotetext{
a Schedule 140 pipe 508-mm O.D. fabricated by Cameron Iron Works, Heat J-7201. Actual heat treatment not known.

b Hot-pressed plate $162 \mathrm{~mm}$ thick from Midland reactor lower head. Austenitized at $871-899^{\circ} \mathrm{C}$ for $5.5 \mathrm{~h}$ and brine quenched, then tempered at $649-663^{\circ} \mathrm{C}$ for $5.5 \mathrm{~h}$ and brine quenched. The plate was machined to a final thickness of $127 \mathrm{~mm}$. The I.D. surface was inlaid with $4.8-\mathrm{mm}$ weld cladding and stress relieved at $607^{\circ} \mathrm{C}$ for $23.8 \mathrm{~h}$.
}

Table 2. Average room-temperature tensile properties of ferritic steels

\begin{tabular}{rcccc}
\hline & $\begin{array}{c}\text { Yield } \\
\text { Stress } \\
\text { Material }\end{array}$ & $\begin{array}{c}\text { Ultimate } \\
\text { Stress } \\
(\mathrm{MPa})\end{array}$ & $\begin{array}{c}\text { Elongation } \\
(\%)\end{array}$ & $\begin{array}{c}\text { Reduction } \\
\text { in Area } \\
(\%)\end{array}$ \\
\hline A106-Gr B & 301 & 572 & 23.5 & 44.0 \\
A533-Gr B & 431 & 602 & 27.8 & 66.6 \\
\hline
\end{tabular}


Table 3. Fatigue results for A533-Gr B steel in air and water environments

\begin{tabular}{|c|c|c|c|c|c|c|c|c|c|}
\hline \multirow[b]{2}{*}{ Test No. } & \multirow[b]{2}{*}{ Environ. ${ }^{a}$} & \multirow{2}{*}{$\begin{array}{c}\text { Temp. } \\
\left({ }^{\circ} \mathrm{C}\right)\end{array}$} & \multirow{2}{*}{$\begin{array}{c}\text { Strain } \\
\text { Range (\%) }\end{array}$} & \multicolumn{2}{|c|}{ Strain Rate $(\% / \mathrm{s})$} & \multirow{2}{*}{$\begin{array}{c}\text { Stress } \\
\text { Range (MPa) }\end{array}$} & \multirow{2}{*}{$\begin{array}{l}\text { Life } \mathrm{N}_{25} \\
\text { (Cycles) }\end{array}$} & \multirow{2}{*}{$\begin{array}{l}\text { Number } \\
\text { of Blocks }\end{array}$} & \multirow[b]{2}{*}{ CUF $^{b}$} \\
\hline & & & & Ten. & Comp. & & & & \\
\hline \multicolumn{10}{|c|}{ A533-Gr B Low-Alloy Steel } \\
\hline 1785 & Air & 25 & 0.76 & 0.4 & 0.4 & 763.7 & 8,840 & c & 0.974 \\
\hline 1779 & & & 0.76 & 0.004 & 0.4 & 759.8 & 5,960 & c & 0.657 \\
\hline 1786 & & & 0.40 & 0.4 & 0.4 & 687.7 & 61,100 & c & 0.513 \\
\hline 1533 & PWR & 288 & 0.77 & 0.004 & 0.4 & 916.0 & 3,416 & - & 0.812 \\
\hline 1818 & & & 0.80 & 0.004 & 0.4 & 919.0 & 2,030 & $5^{d}$ & 0.536 \\
\hline 1645 & High DO & 288 & 0.72 & 0.4 & 0.4 & 831.1 & 2,736 & - & 0.819 \\
\hline 1626 & & & 0.79 & 0.004 & 0.4 & 910.1 & 247 & - & 0.794 \\
\hline 1715 & & & 0.81 & 0.004 & 0.4 & 904.1 & 381 & - & 1.310 \\
\hline 1718 & & & 0.81 & 0.004 & 0.4 & 904.3 & 346 & - & 1.190 \\
\hline 1800 & & & 0.81 & 0.004 & 0.4 & 897.9 & 303 & $5^{e}$ & 1.042 \\
\hline 1803 & & & 0.82 & 0.004 & 0.4 & 913.9 & 272 & $7^{f}$ & 0.966 \\
\hline 1641 & & & 0.39 & 0.4 & 0.4 & 693.0 & 17,367 & - & 0.387 \\
\hline 1665 & & & 0.38 & 0.004 & 0.4 & 717.0 & 3,455 & - & 0.522 \\
\hline 1815 & & & 0.38 & 0.004 & 0.4 & 735.8 & 2,200 & $5 g$ & 0.332 \\
\hline \multicolumn{10}{|c|}{ A106-Gr B Carbon Steel } \\
\hline 1619 & Air & 288 & 0.40 & 0.4 & 0.4 & 741.7 & 37,142 & - & 0.844 \\
\hline 1636 & & & 0.40 & 0.4 & 0.4 & 749.6 & 34,829 & - & 0.791 \\
\hline 1634 & High DO & 288 & 0.40 & 0.4 & 0.4 & 733.2 & 19,318 & - & 0.743 \\
\hline 1624 & & & 0.46 & 0.004 & 0.4 & 775.7 & 2,276 & - & 2.104 \\
\hline 1639 & & & 0.42 & 0.004 & 0.4 & 751.6 & 2,951 & - & 1.940 \\
\hline 1816 & & & 0.43 & 0.004 & 0.4 & 759.6 & 1,410 & $5 \mathrm{~g}$ & 1.015 \\
\hline
\end{tabular}

aPWR $=$ simulated PWR water containing $2 \mathrm{ppm}$ lithium and $1000 \mathrm{ppm}$ boron, and high-DO = deionized water with $0.6-0.8 \mathrm{ppm}$ dissolved oxygen.

${ }^{b}$ Fatigue usage factor based on the statistical model, i.e., usage = observed life/life estimated from the model.

cInterrupted periodically to allow for surface replication.

dEvery 450 cycles, a block of 170 fast/fast cycles at $0.4 \%$ strain range and $0.4 \% / \mathrm{s}$ strain rate.

Every 50 cycles, a block of 170 fast/fast cycles at $0.4 \%$ strain range and $0.4 \% / \mathrm{s}$ strain rate.

Every 30 cycles, a block of 170 fast/fast cycles at $0.4 \%$ strain range and $0.4 \% / \mathrm{s}$ strain rate.

gEvery 420 cycles, a block of 500 fast/fast cycles at the same strain range but $0.4 \% / \mathrm{s}$ strain rate.

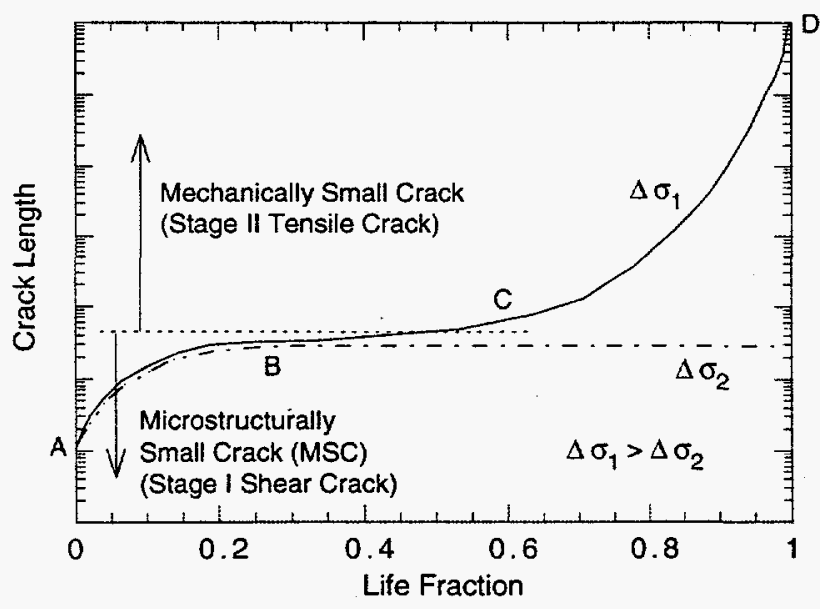

Figure 1.

Growth of cracks in smooth fatigue specimens 

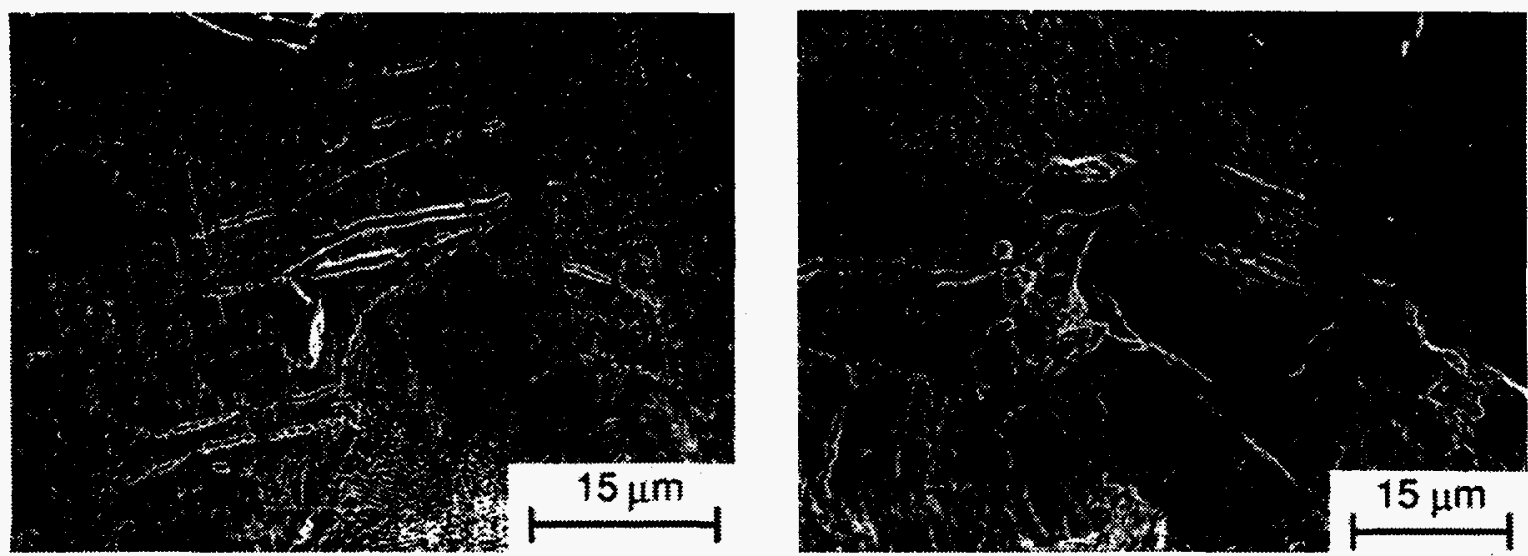

Figure 2. Surface cracks along slip bands, carbide particles, and ferrite-pearlite phase boundaries of A106-Gr B steel

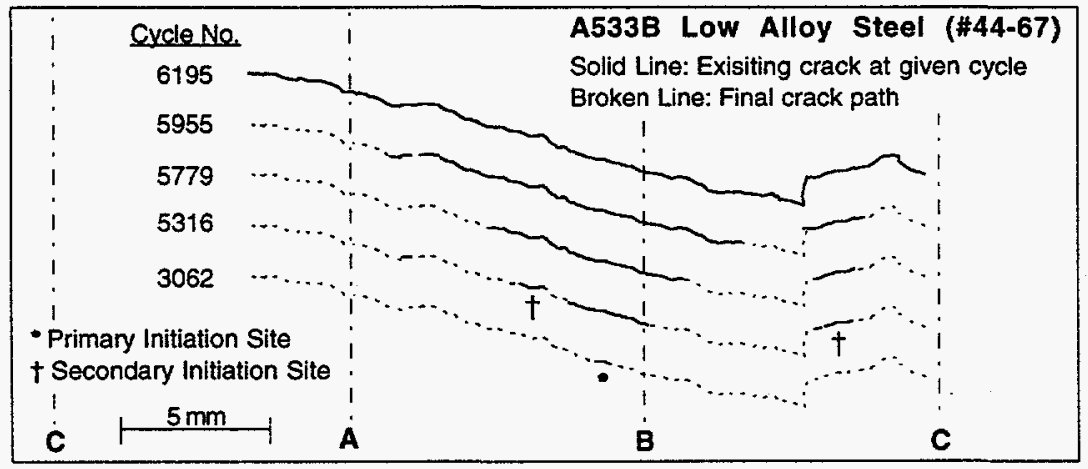

Figure 3. Morphology and length of surface crack after various numbers of cycles for A533-Gr B steel tested in air at room temperature, $0.75 \%$ strain range, and slow/fast sawtooth waveform 

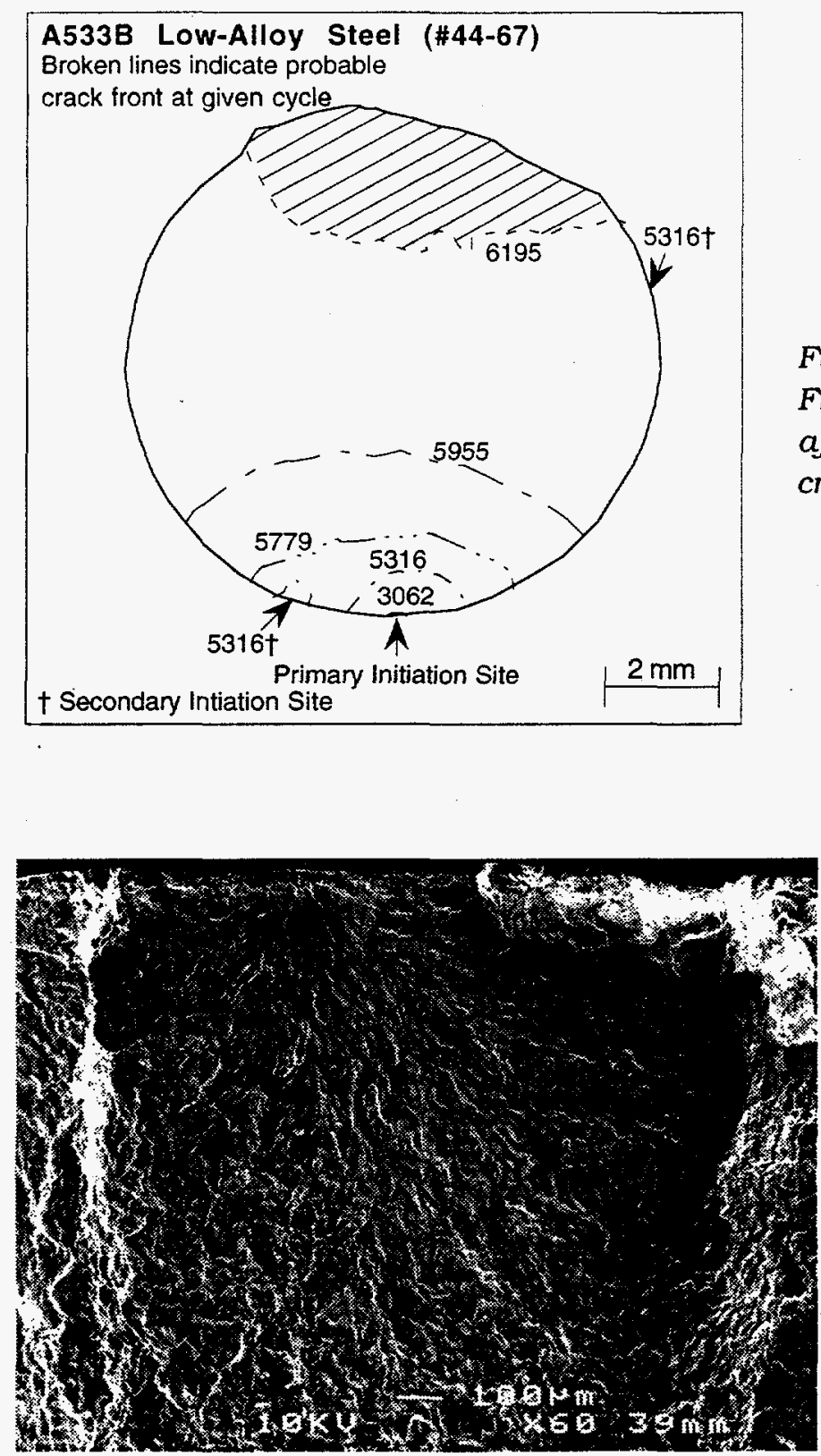

Figure 4.

Fracture surface and probable crack front after different fatigue cycles for surface crack shown in Fig. 3
Figure 5.

Beach marks produced from four of five block loading sequences on fracture surface of A533-Gr B steel tested at $288^{\circ} \mathrm{C}$ in high-dissolvedoxygen water 


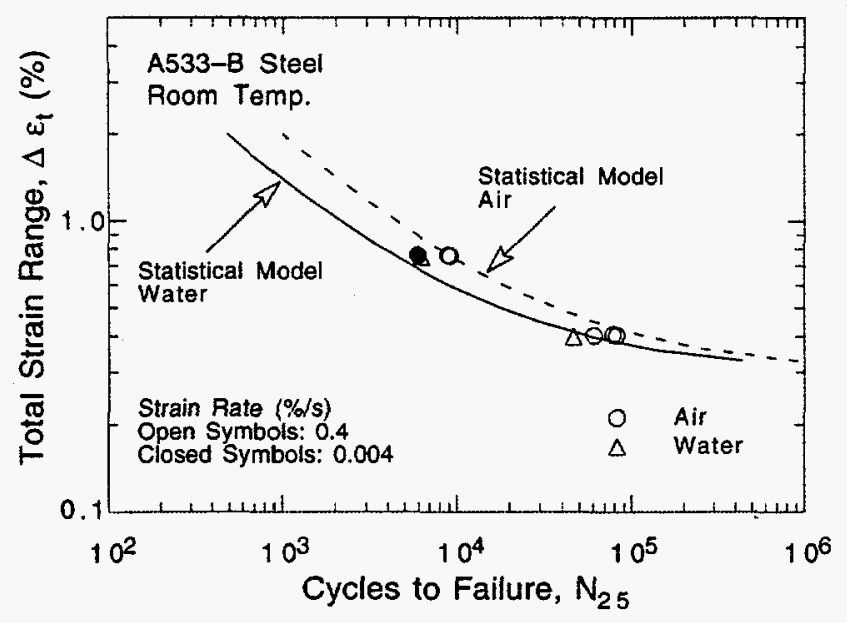

Figure 6.

Fatigue lives of $A 533-G r B$ steel tested at room temperature in air and highdissolved-oxygen water
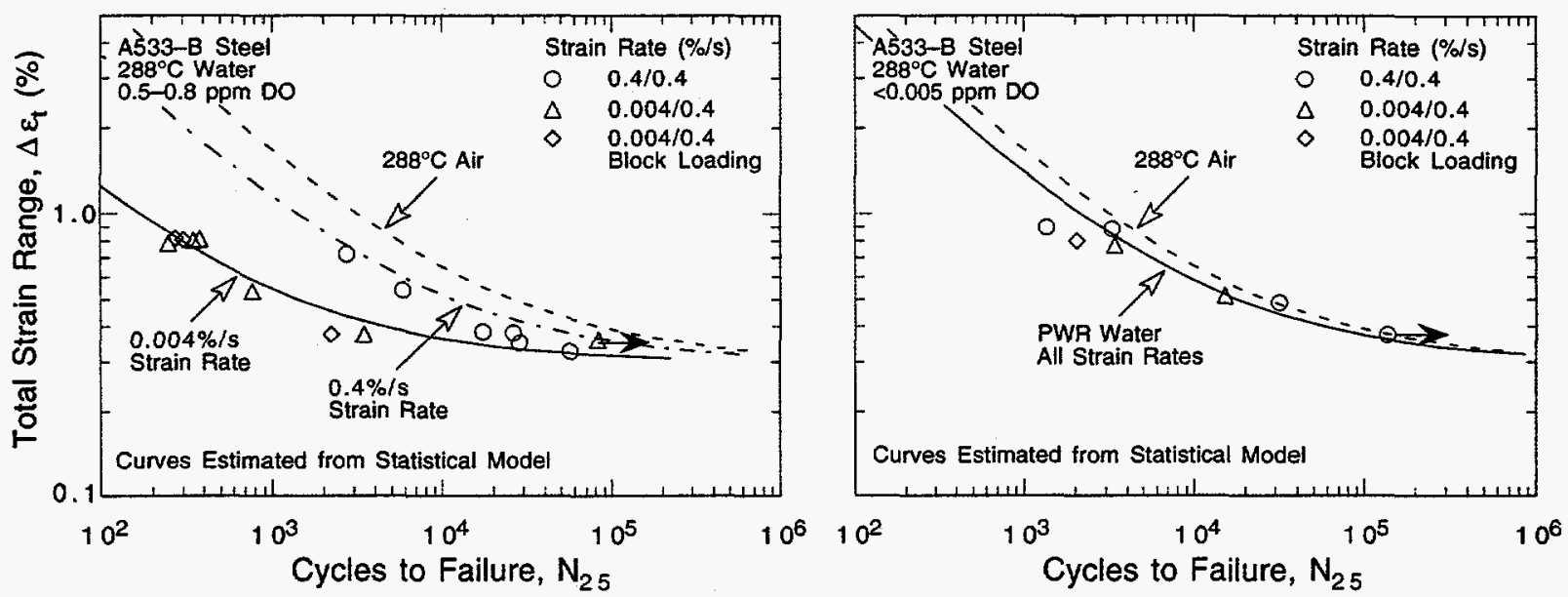

Figure 7. Fatigue lives of A533-Gr B steel tested at $288^{\circ} \mathrm{C}$ in simulated PWR and highdissolved-oxygen water

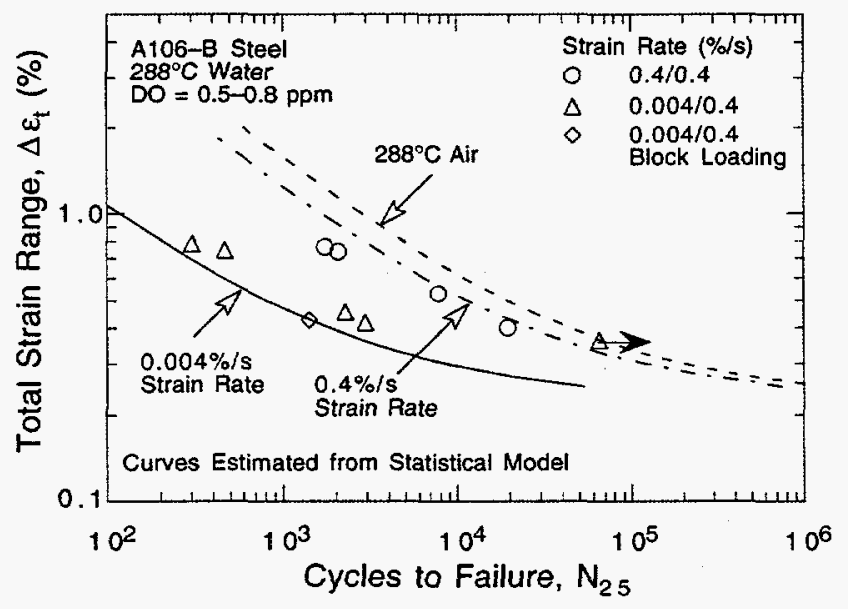

Figure 8.

Fatigue lives of A106-Gr B steel tested at $288^{\circ} \mathrm{C}$ in high-dissolved-oxygen water 


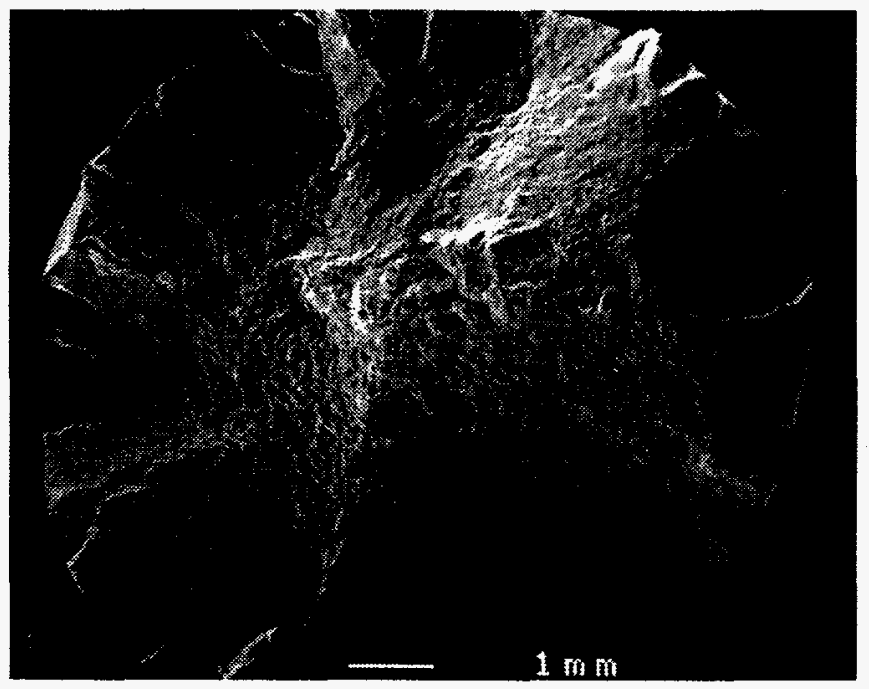

(a)

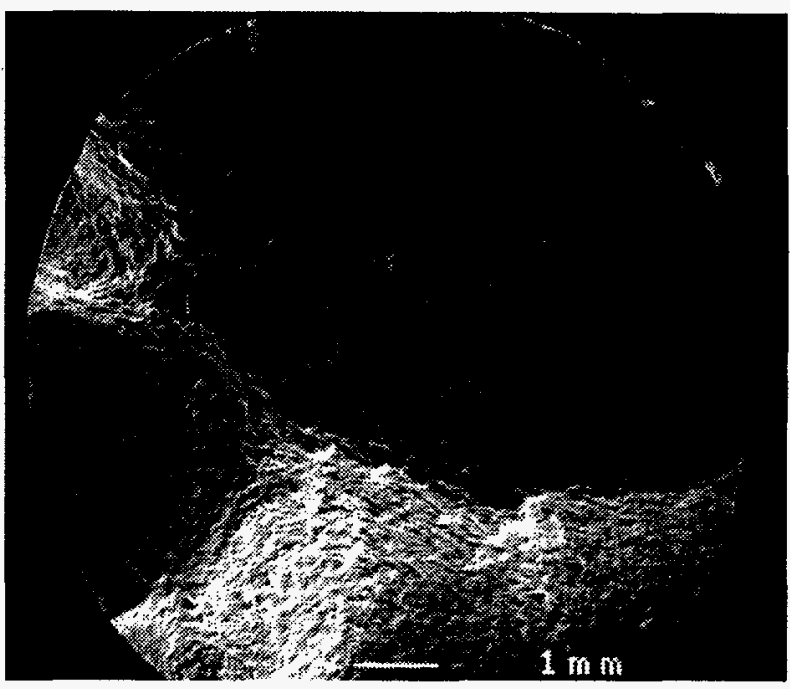

(b)

Figure 9. Photomicrographs of fractured specimens tested with slow/fast waveform at (a) $0.8 \%$ strain range interrupted every 30 cycles and subjected to 170 cycles at lower strain range, and (b) $0.38 \%$ strain range interrupted every 420 cycles and subjected to 170 cycles at fast strain rate
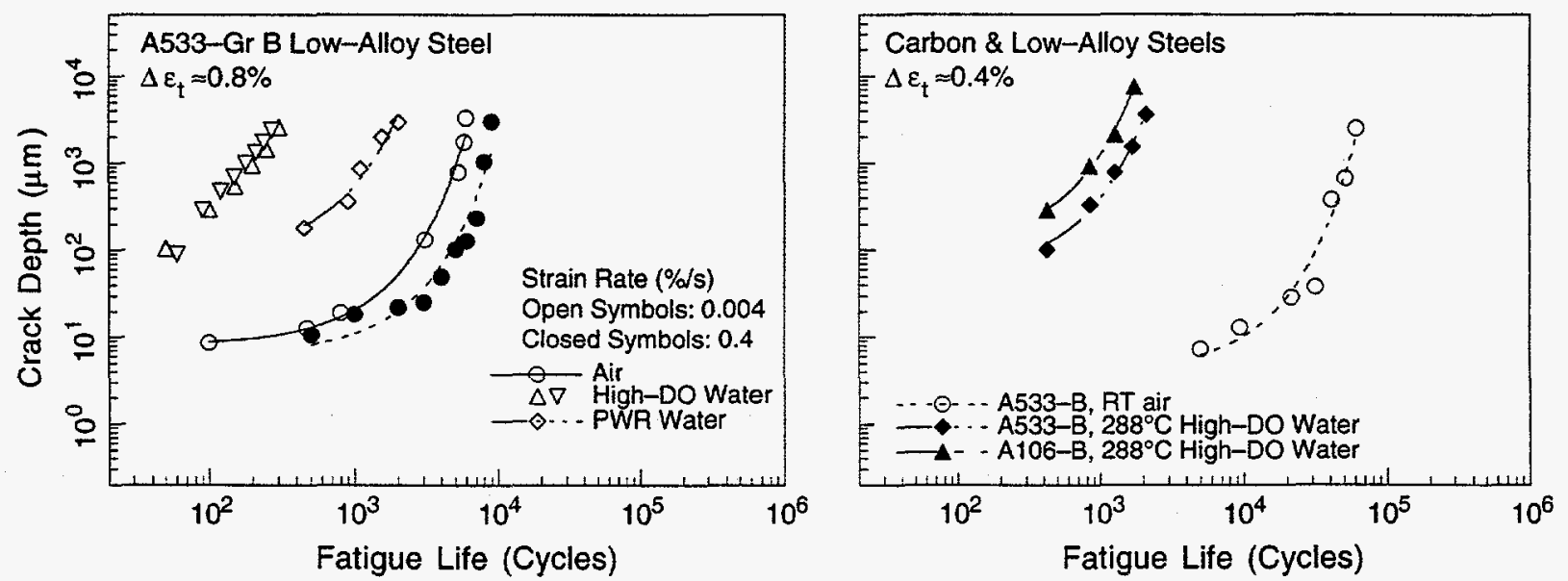

Figure 10. Depth of largest crack plotted as a function of fatigue cycles for A533-Gr B low-alloy steel and A106-Gr B carbon steel in air and water environments 

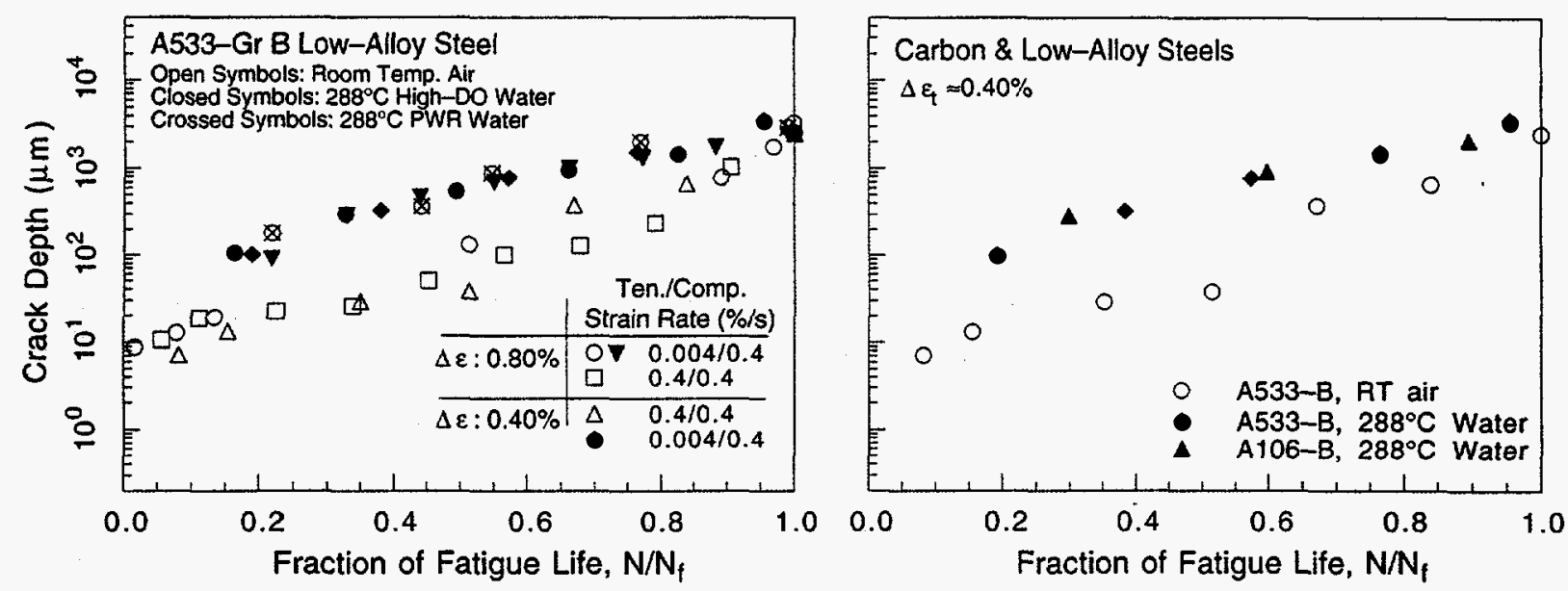

Figure 11. Depth of largest crack plotted as a function of fractional life for A533-Gr B low-alloy steel and A106-Gr B carbon steel in air and water environments
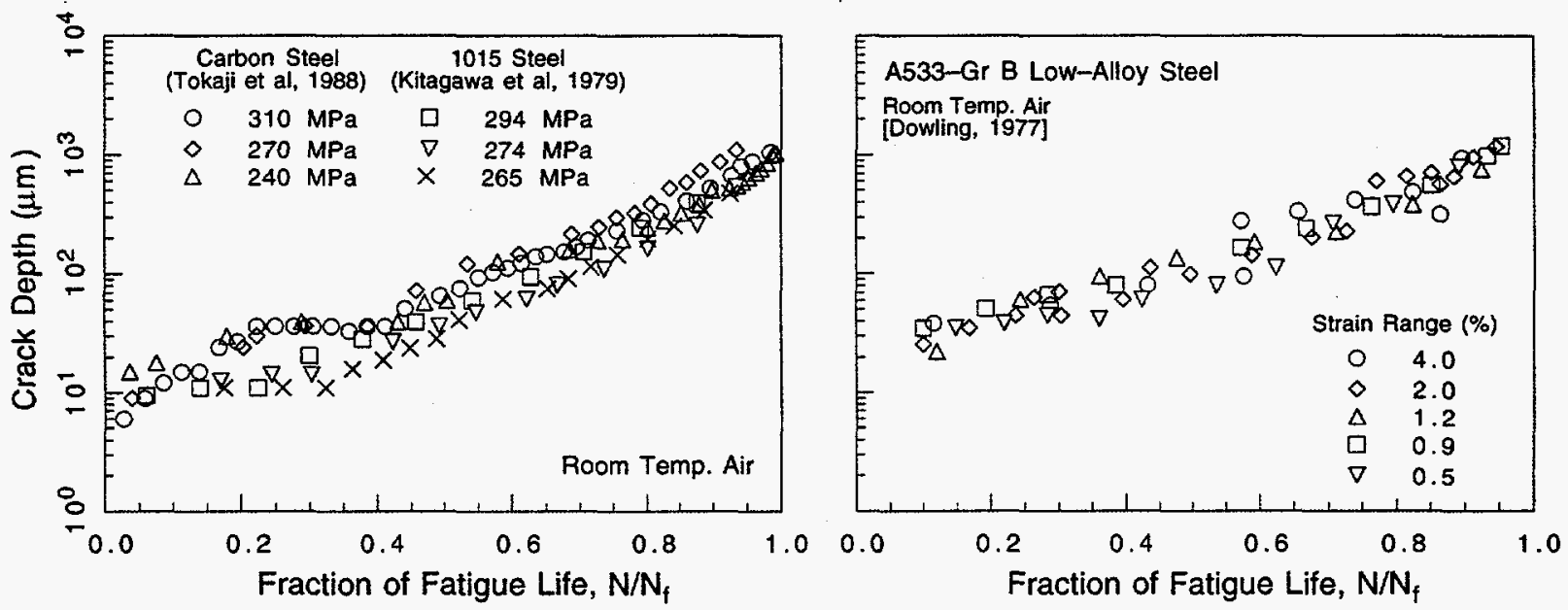

Figure 12. Crack depth plotted as a function of fractional life for carbon and low-alloy steels tested in room-temperature air 

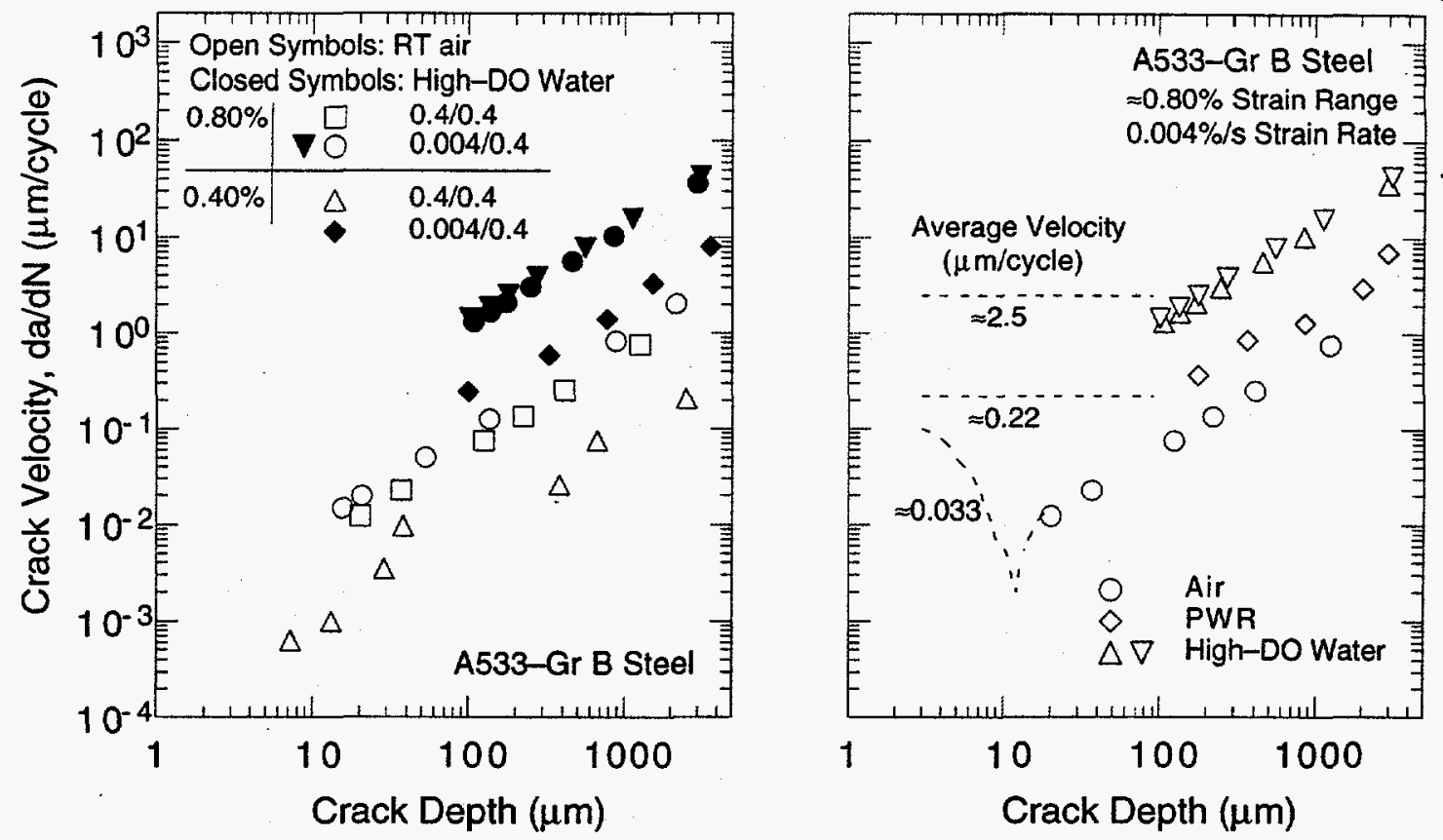

Figure 13. Crack growth rates plotted as a function of crack depth for A533-Gr B low-alloy steel tested in air and water environments 
A533-Gr B low-alloy steel
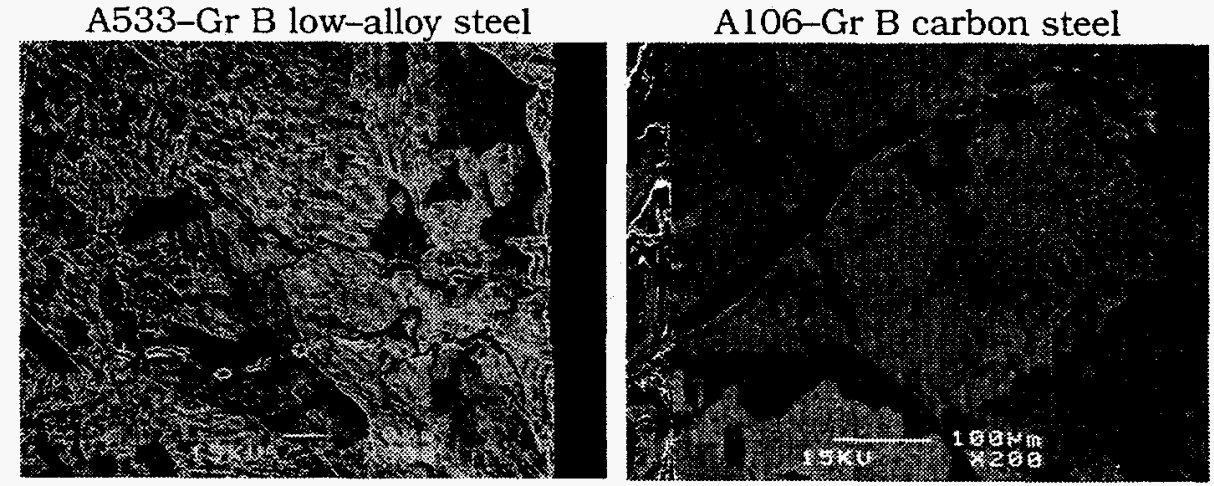

Air
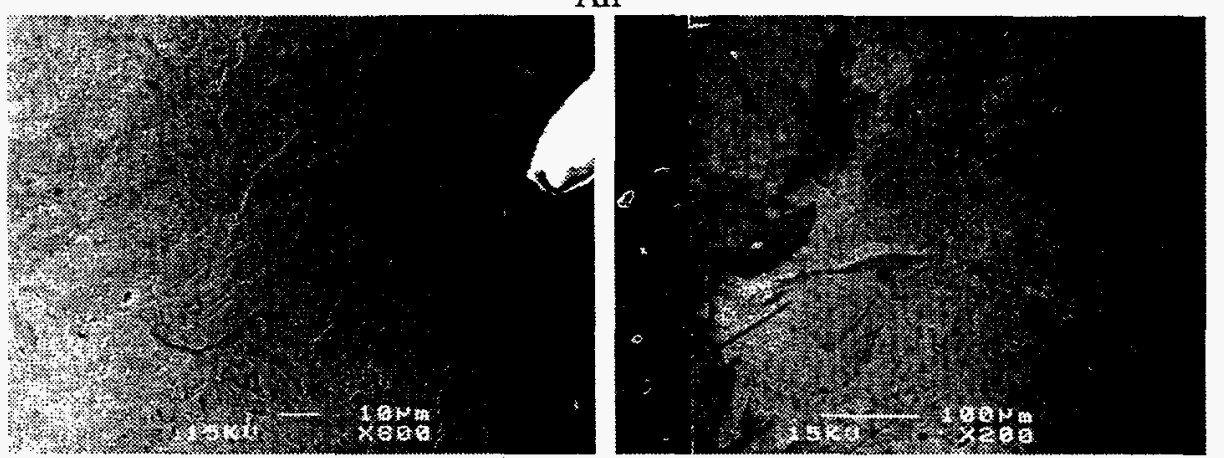

Simulated PWR Water
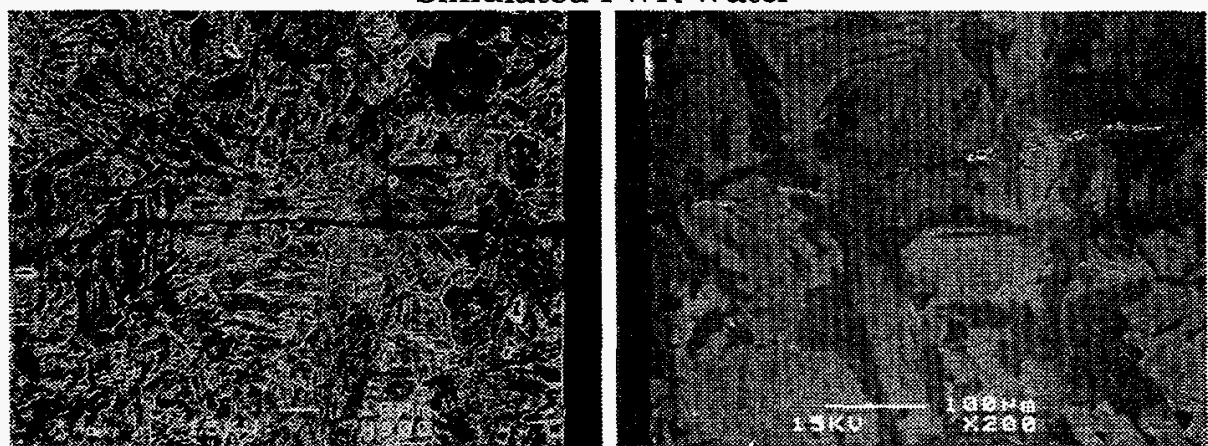

Water with $\approx 0.7 \mathrm{ppm}$ Dissolved Oxygen

Figure 14. Photomicrographs of surface cracks along longitudinal sections of A533-Gr B lowalloy steel and A106-Gr B carbon steel in air, high-dissolved-oxygen water, and simulated PWR environments 


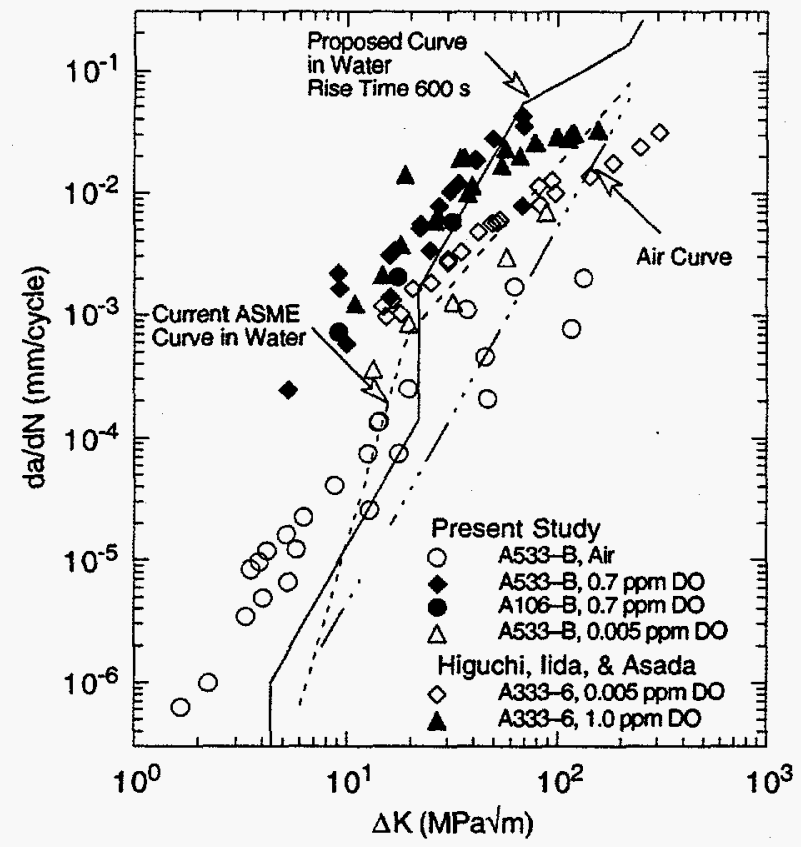

Figure 15.

Crack growth rates determined from smooth cylindrical fatigue test specimens and ASME Section XI reference curves for carbon and low-alloy steels in air and water environments 